\title{
Application genetic algorithms for load management in refrigerated warehouses with wind power penetration
}

Zong, Yi; Cronin, Tom; Gehrke, Oliver; Bindner, Henrik W.; Hansen, Jens Carsten; Latour, Mikel Iribas; Arcauz, Oihane Usunariz

Published in:

PowerTech, 2009 IEEE Bucharest

Link to article, DOI:

10.1109/PTC.2009.5282071

Publication date:

2009

Document Version

Publisher's PDF, also known as Version of record

Link back to DTU Orbit

Citation (APA):

Zong, Y., Cronin, T., Gehrke, O., Bindner, H. W., Hansen, J. C., Latour, M. I., \& Arcauz, O. U. (2009).

Application genetic algorithms for load management in refrigerated warehouses with wind power penetration. In PowerTech, 2009 IEEE Bucharest (Vol. 1-5, pp. 1361-1366). IEEE Power and Energy Society.

https://doi.org/10.1109/PTC.2009.5282071

\section{General rights}

Copyright and moral rights for the publications made accessible in the public portal are retained by the authors and/or other copyright owners and it is a condition of accessing publications that users recognise and abide by the legal requirements associated with these rights.

- Users may download and print one copy of any publication from the public portal for the purpose of private study or research.

- You may not further distribute the material or use it for any profit-making activity or commercial gain

- You may freely distribute the URL identifying the publication in the public portal 


\title{
Application genetic algorithms for load management in refrigerated warehouses with wind power penetration
}

\author{
Yi Zong, Tom Cronin, Oliver Gehrke, Henrik Bindner, Jens Carsten Hansen, Mikel Iribas Latour, \\ Oihane Usunariz Arcauz
}

\begin{abstract}
Wind energy is produced at random times, whereas the energy consumption pattern shows distinct demand peaks during day-time and low levels during the night. The use of a refrigerated warehouse as a giant battery for wind energy is a new possibility that is being studied for wind energy integration as well as a way to store electricity produced during night-time by wind turbines. The controller for load management in a refrigerated warehouse with wind power penetration by GAbased is introduced in this paper. The objective function is to minimize the energy consumption for operating the refrigerated warehouse. It can be seen that the GA-based control strategy achieves feasible results for operating the temperature in refrigerated warehouse. Balancing the wind power production with refrigerated warehouse load management promises to be a clean and cost effective method. For refrigerated warehouse owners, it has the potential to lower operational costs.
\end{abstract}

Index Terms--Genetic algorithm, load management, optimization, wind energy

\section{INTRODUCTION}

$\mathrm{T}$ HE integration of wind power into the national or EU energy supply systems is becoming more problematic with increasing installed capacity and production, due to a mismatch of supply and demand of energy. In order to

This work was supported by the Night Wind project, which is a Specific Targeted Research Project under the European Commission 6th Framework Programme. The full title is, "Grid Architecture for Wind Power Production with Energy Storage through load shifting in Refrigerated Warehouses".

Yi Zong is with the Wind Energy Division, Risø DTU, National Laboratory for Sustainable Energy, P.O. box 49, DK-4000 Roskilde, Denmark, (phone: +45-4677-5045; fax: +45-4677-5083; e-mail: yi.zong@risoe.dk).

Tom Cronin is with the Wind Energy Division, Risø DTU, National Laboratory for Sustainable Energy, P.O. box 49, DK-4000 Roskilde, Denmark (e-mail: tom.cronin@risoe.dk).

Oliver Gehrke is with the Wind Energy Division, Risø DTU, National Laboratory for Sustainable Energy, P.O. box 49, DK-4000 Roskilde, Denmark. (e-mail: oliver.gehrke@risoe.dk).

Henrik Bindner is with the Wind Energy Division, Risø DTU, National Laboratory for Sustainable Energy, P.O. box 49, DK-4000 Roskilde, Denmark. (e-mail: henrik.bindner@risoe.dk).

Jens Casten Hansen is with the Wind Energy Division, Risø DTU, National Laboratory for Sustainable Energy, P.O. box 49, DK-4000 Roskilde, Denmark. (e-mail: casten.hansen@risoe.dk).

Mikel Iribas Latour is with the National Renewable Energy Center, SpainCENER. (e-mail: miribas@cener.com).

Oihane Usunariz Arcauz is with the National Renewable Energy Center, Spain-CENER. (e-mail: ousunariz@cener.com). accommodate the random production of energy in the grid, it would be most convenient when alternative (renewable and conventional) electricity producers could balance out the difference between production of energy and electricity demand by means of storage. Refrigerated warehouses are major users of electrical energy, day and night. Electricity is converted by the refrigeration installation into thermal energy in refrigerated or frozen products. When the temperature of stored frozen products in the EU is allowed to vary by $1^{\circ} \mathrm{C}$, the warehouses can act as a 50.000 MWh battery on the grid i.e. store over twice the projected 2010 EU average hourly wind power production. In times of high wind supply the temperature in refrigerated warehouses can be lowered, using the "excess energy" and, additionally, decreasing future cooling demand. When wind power availability is low, the storage can be "discharged" by allowing the temperature to rise again. This has the effect of adding a "virtual battery" to the power system with relatively little investment in new hardware. That is, what the EU "Night Wind" project proposes to demonstrate [1].

In this project, a new control strategy based on a Genetic Algorithm (GA) was used to set the temperature in refrigerated warehouses to a level that was derived from the balance between estimated wind energy production and estimated electricity demand. This is the case for "island operation" with delivery of surplus energy to the grid, and also for the case of Distributed Energy Resources (DER), where the wind turbines are physically located elsewhere than the (existing) refrigerated warehouses, but controlled in an interdependent way to support the European energy service network.

The refrigerated warehouse which makes up the demonstration element in the Night Wind project consumes around 12 million $\mathrm{kWh}$ per year. Whilst it is one of the largest in Europe, the fundamental principles of operation are common with other refrigerated warehouse. The major power consumption comes from the compressors within the refrigeration units, whose main loads are the heat transfers from the external environment and from the goods coming into the warehouse at around $-7^{\circ} \mathrm{C}$. The control system at present attempts to use cheaper night-time electricity, but invariably the compressors also need to run at times during the day to keep the temperature below the upper limit [2].

The objective of the control aspect of this project is to minimize electricity consumption costs by optimizing the cooling strategy depending on predicted wind generation and 
grid electricity prices and continually adjusting the power taken from the grid/from the wind turbines. In some cases, it may actually be profitable to cool during the daytime; in other cases, it may be cheaper to export the electricity produced to the grid and then buy it back as needed. In order to meet the requirements for keeping the products frozen, there are totally three compressor sets in the refrigerated warehouse. One compressor is always working and the second compressor is on for regulating the air temperature between $-21{ }^{\circ} \mathrm{C}$ and $18^{\circ} \mathrm{C}$. If the air temperature is higher than $-18^{\circ} \mathrm{C}$, then the three compressors are working at the same time. Each compressor set consumes $375 \mathrm{~kW}$ at maximum cooling capacity.

\section{CONTROLLER DESIGN BASED ON GENETIC ALGORITHM}

\section{A. Genetic Algorithm}

The genetic algorithm is a search algorithm based on the mechanics of natural selection and natural genetics. It is often applied to solve various optimization problems that are not well suited for standard optimization algorithms, including problems in which the objective function is discontinuous, non-differentiable, stochastic or highly nonlinear. It has been shown that the genetic algorithm can not only provide approximate global optimum solution, but also it does not require any training of data and will never have convergence problems [3]. The general concept of a genetic algorithm can be illustrated as in Fig. 1 and the detailed algorithm for a GA based on minimum cost in the project is given below:

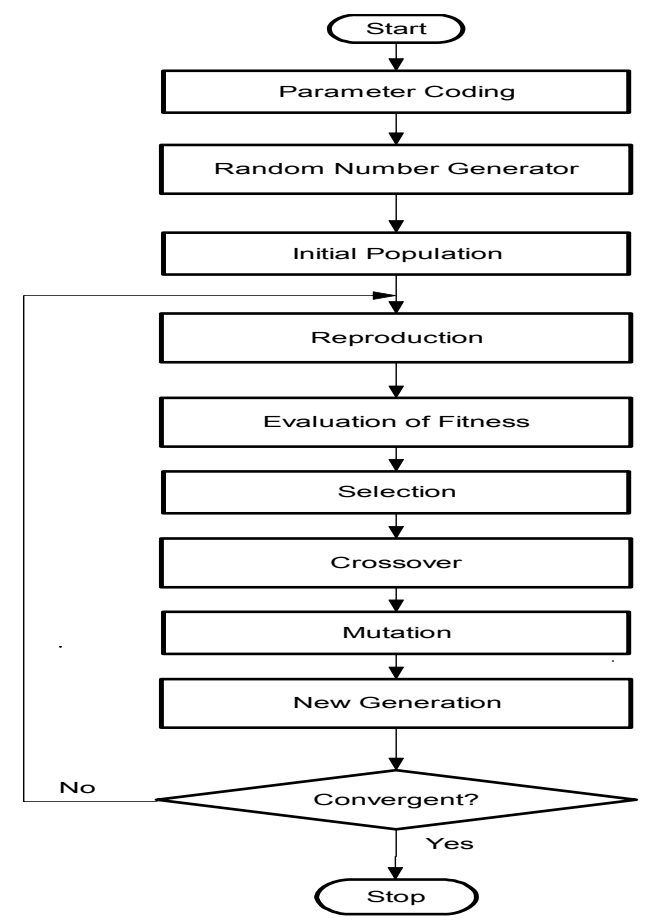

Fig. 1. Flowchart of GA

1. Generate the random population for the reference air temperature for Gen $=1$, which is a random real number belonging to the interval $[-21,-18]$. The initial population should be selected so that the diversity is guaranteed which helps finding the global optimum solution quickly.

2. Use the refrigerated warehouse model to obtain various air temperature and product temperature and to determine how many hours should be optimized in the time ahead.

3. Evaluate the fitness of each individual and determine the best one by calculating the cost and then transfer it to the next generation.

4. Select individuals for reproduction with roulette wheel selection strategy.

5. Employ the crossover operator with a probability equal to 0.6 to favor exchange of genetic information among the population.

6. Apply the mutation operator with a probability equal to 0.05 by replacing the old individual to obtain new individuals for next generation.

7. Check for convergence by measuring the diversity of the population. Repeat steps 2 to 6 until the difference between best fitness and average fitness is less than specified error. Otherwise, stop.

\section{B. Genetic operations}

The performance of a GA depends on a good combination of all parameters. In the proposed algorithm, the roulettewheel selection method was employed. In this selection method, the diversity of population can be maintained and the best individuals can survive in the new generation. The evolution was processed for 100 generations with a population size equal to $73(2 n+1=2 \times 36+1$, where $n$ is the number of design variables, i.e. the optimized reference air temperatures in the next 36 hours).

Theoretically, the population size affects both the ultimate performance and the efficiency of GAs [4]. GAs generally perform poorly with very small populations, because the population provides an insufficient sample size for most hyper planes. A large population is more likely to contain representatives from a large number of hyper planes. Hence, the GAs can perform a more informed search. As a result, a large population discourages premature convergence to suboptimal solutions. On the other hand, a large population requires more evaluations per generation, possibly resulting in an unacceptably slow rate of convergence.

The crossover rate controls the frequency with which the crossover operator is applied. The higher the crossover rate, the more quickly new structures are introduced into the population. If the crossover rate is too high, high-performance structures are discarded faster than selection can produce improvements. If the crossover rate is too low, the search may stagnate due to the lower exploration rate. A two points crossover was used with a value of 0.6. It is quicker to get the same results and retain the solutions much longer than one point crossover.

Mutation is a secondary search operator which increases the variability of the population. A high level of mutation introduces too much diversity and takes a longer time to arrive at the optimal solution. A low level of mutation tends to miss some near-optimal points. After the speed comparison in 
different experiments, the mutation operator with a probability equal to 0.05 was assigned in the algorithm.

The process of generating new trials with the best fitness will be continued based on the difference between best fitness and average fitness being less than specified error. The convergence criteria could provide not only sufficient reduction in CPU time but also maintain the acceptable accuracy in overall results.

\section{Temperature controller design based on GA}

By studying the model of the refrigerated warehouse, it is important to observe that there is no "continuous" control for the compressors, or for the reference air temperatures. The implemented controller is an $O N / O F F$ controller. If the temperature is below the estimated reference value minus the tolerance value, then the compressors switch $O F F$. If the temperature is higher than the estimated reference value plus the tolerance value, then the compressors switch ON. At most 36 air temperatures' reference values were optimized for the next 36 hours. The number of the optimized variables are less than or equal to 36 , because the electricity price is known at 12 o'clock each day for the following day in hours intervals. There is an actual horizon of 36 hours where all the information (forecast or agreed) is known. The compressors are switched $O N / O F F$, if the temperatures vary within a margin of $+/-0.1^{\circ} \mathrm{C}$. The range for the air temperature is currently in $\left[-21^{\circ} \mathrm{C},-18^{\circ} \mathrm{C}\right]$. All the information for the next 36 hours about the wind power prediction, ambient temperature forecasts and electricity buy/sale price were integrated into the controller's program as input files. The parameters of the refrigerated warehouse (e.g. store volume, product volume, heat capacity of product and product specific mass, etc.) were all defined as constants in the $\mathrm{C}++$ program.

It is well known that Matlab is a power tool for theory analysis and algorithm simulation prior to programming. But, the drawback of Matlab is its runtime. It probably takes hundred times of an equivalent $\mathrm{C}++$ programme. Loops are particularly slow in Matlab. This is because Matlab has an interpreter, which is much slower than $\mathrm{C}++$. However, for real-time application, the processing delay is a critical issue. In this case, we switched over to $\mathrm{C}++$ after some initial testing of the algorithm in Matlab. Finally, it proved that $\mathrm{C}++$ is more efficient. For example, in section IV, the first scenario, if it was realized using Matlab, the whole algorithm process took at least 2.5 hours; while in $\mathrm{C}++$, it only needs no more than 2 minutes.

A GAlib (A C++ library of genetic algorithm components) was used to obtain the optimized temperature in the refrigerated warehouse. We worked primarily with two classes: a genome and a genetic algorithm [5]. The library contains four types of genomes:

GAListGenome,GATreeGenome, GAArrayGenome, and GABinaryStringGenome. Here the GAArrayGenome was used together with real numbers in the genome. Each genome has three primary operators: initialization, mutation, and crossover. There are many different types of genetic algorithms. GAlib includes three basic types: 'simple', 'steady-state', and 'incremental'. These algorithms differ in the way that they create new individuals and replace old individuals during the course of an evolution. The simple genetic algorithm was applied to realize the control strategy (See Fig.2).

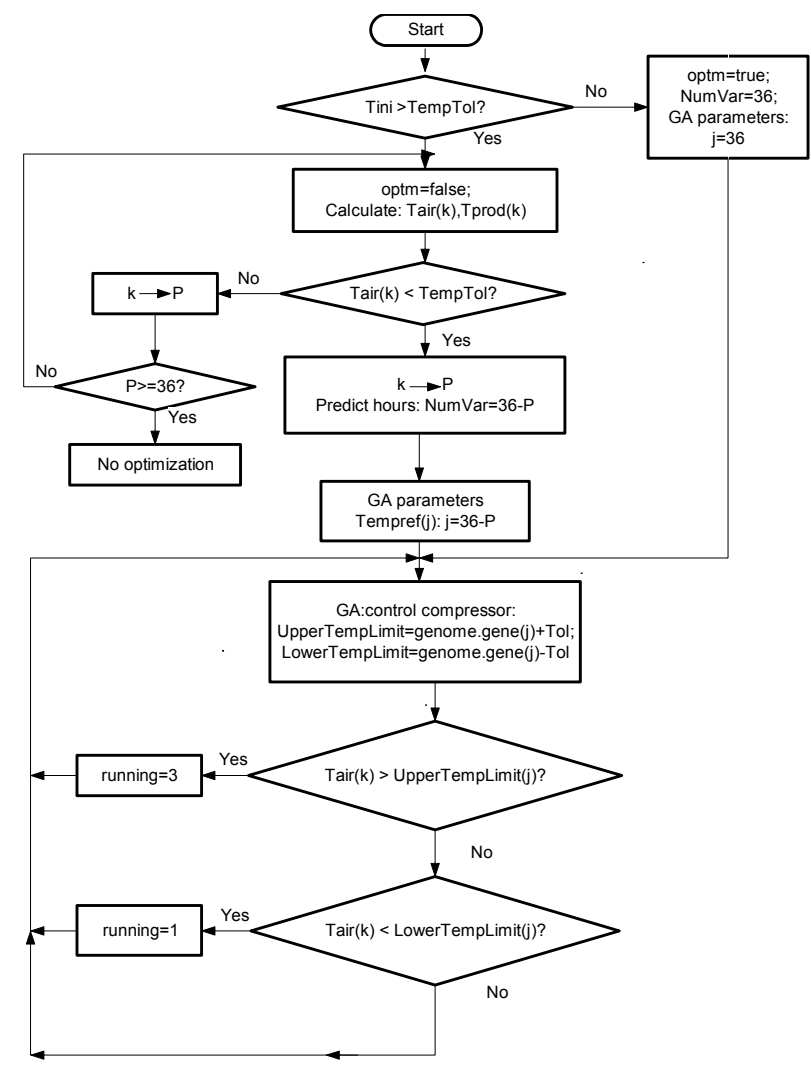

Fig. 2. Flowchart of control based on GA

\section{RESULTS}

Before analyzing the results, let us comment some important details. First of all, the initial population is the initial reference temperature in the algorithm for the next 36 hours. Secondly, the tolerant temperature (See TempTol in Fig.2) is a threshold value. When the (initial) air temperature in the refrigerated warehouse is higher than it, the compressors are supposed to be always ON, and the GA is not working (See Fig. 2 optm=false). Otherwise, the GA is called to optimize the compressors' performance. Finally, the range for the optimized air temperature $\left[-21^{\circ} \mathrm{C},-18^{\circ} \mathrm{C}\right]$ determinates the limits for the reference air temperatures, where UpperTempLimit $=$ genome.gene $(j)+$ Tol LowerTempLimit=genome.gene(j)-Tol.

The results are described for the three different scenarios. The initial air temperature in these three scenarios is different. The number of generation for the genetic algorithm is all defined as 100. The control and GA parameters are shown in Table I. The optimized reference air temperature (genome.gene( $j$ ), $j \in$ int $[0,35])$ in the different scenarios equals the upper reference temperature minus the margin or the lower reference temperature plus the margin, where the margin is $0.1^{\circ} \mathrm{C}$. The Figs.3-5 show the results of the first scenario. They present the variation of optimized reference temperatures, compressors' working status, and different power (e.g. power 
consumption of compressors \& predicted wind power) by the GA controller, respectively. In the same way, Figs.6-8 describe the results of the second scenario and the unique difference is that the optimized time (as the $x$ axis shown in Figs. 5-8). For the first scenario, the optimized time is 36 hours (2160 minutes) and the second one; the optimized time is 25 hours (1500 minutes).

Table I. Temperature control parameters and the best generation for different

\begin{tabular}{|c|c|c|c|c|}
\hline $\begin{array}{c}\text { No. of } \\
\text { scenario }\end{array}$ & $\begin{array}{c}\text { Initial air } \\
\text { temperature }\end{array}$ & $\begin{array}{c}\text { Tolerant } \\
\text { temperature }\end{array}$ & $\begin{array}{c}\text { Population } \\
\text { size }\end{array}$ & $\begin{array}{c}\text { The best } \\
\text { generation }\end{array}$ \\
\hline 1 & -19.1 & -19 & 73 & 97 \\
\hline 2 & -18.4 & -19 & 73 & 30 \\
\hline 3 & -18 & -19 & - & - \\
\hline
\end{tabular}

In scenario 1 , the initial air temperature is set to $-19.1^{\circ} \mathrm{C}$, and it is $0.1^{\circ} \mathrm{C}$ lower than the tolerant temperature, $-19^{\circ} \mathrm{C}$. From the beginning, the compressors are switching on and off continually, based on the optimized reference temperature's variation in the next 36 hours. The results of the GA optimization are shown in Fig. 3 and it shows the variation of reference temperature over the 36 hour period of optimization. The pattern of compressor activity can be seen in Fig.4. The compressor consumes the energy in four different sets of time, so we can sell the wind energy in the other periods of time (see Fig. 4 \& Fig.5). In this way, the best fitness function is negative $\left(-1918.79 €\right.$, obtained in the $97^{\text {th }}$ generation), which means that the owner can sell the energy and make profit.

In scenario 2 , the initial air temperature is set to $-18.4^{\circ} \mathrm{C}$ which is $0.6{ }^{\circ} \mathrm{C}$ above the tolerant temperature, $-19^{\circ} \mathrm{C}$. Comparing with the scenario 1 , it is logical that from the beginning, 11 hours are needed for the compressors to operate and the genetic algorithm is not called. Then, the compressors are switching on and off continually, based on the air temperature's variation in the next 25 hours (see Fig.6). The compressor consumes the energy in two different sets of time, so we can sell the wind energy in the other periods of time (see Fig. 7 \& Fig. 8). In this way, the best fitness function is negative $\left(-1209.71 €\right.$, obtained in the $30^{\text {th }}$ generation), which means that grid can also obtain the some economical benefits, but not as much as in the scenario 1 .

In scenario 3 , the initial air temperature is set to $-18^{\circ} \mathrm{C}$, and it is $1^{\circ} \mathrm{C}$ higher than the tolerant temperature, $-19^{\circ} \mathrm{C}$. Comparing with the scenario 2 , it is logical that from the beginning, more hours (here more than 36 hours) are needed for the compressor to be $\mathrm{ON}$ to make the air temperature be less than or equal to the tolerant temperature. Finally, in the next 36 hours the control based on the genetic algorithm is not executed.

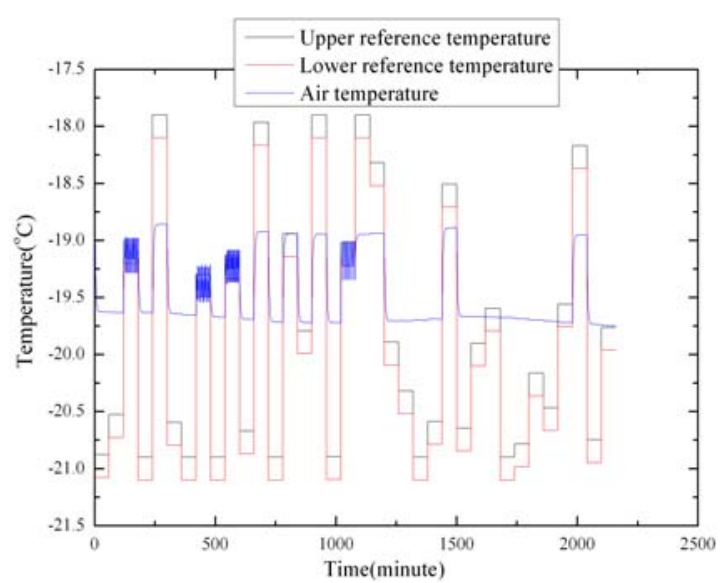

Fig. 3 Optimized upper and lower reference temperature and air temperature for the next 36 hours

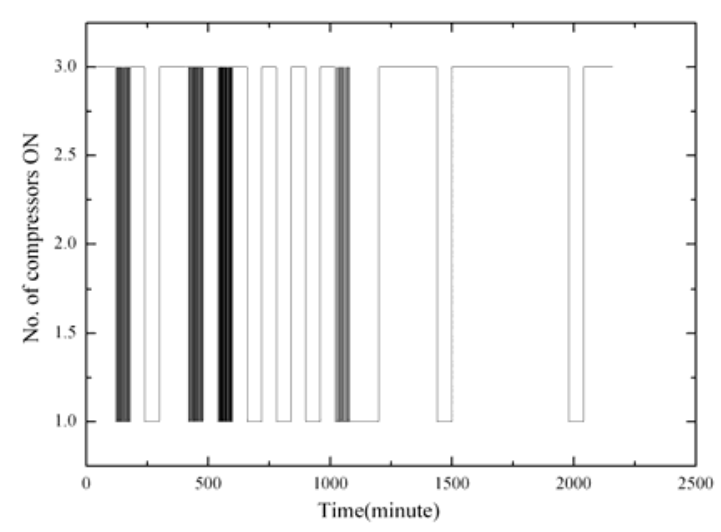

Fig. 4 Number of working compressors

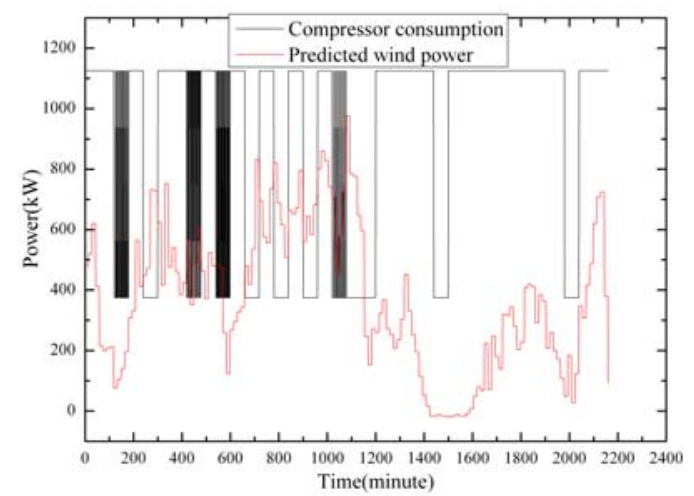

Fig. 5. Compressor consumption and predicted wind power for the next 36 hours 


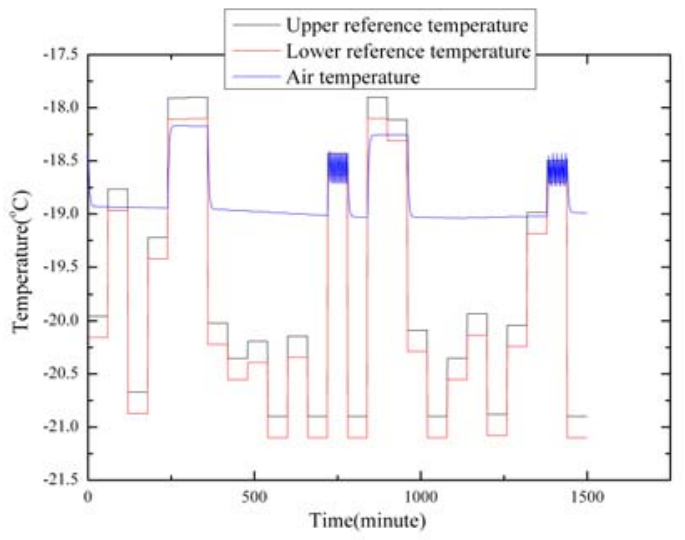

Fig. 6. Optimized upper \& lower reference temperature and air temperature for the next 25 hours

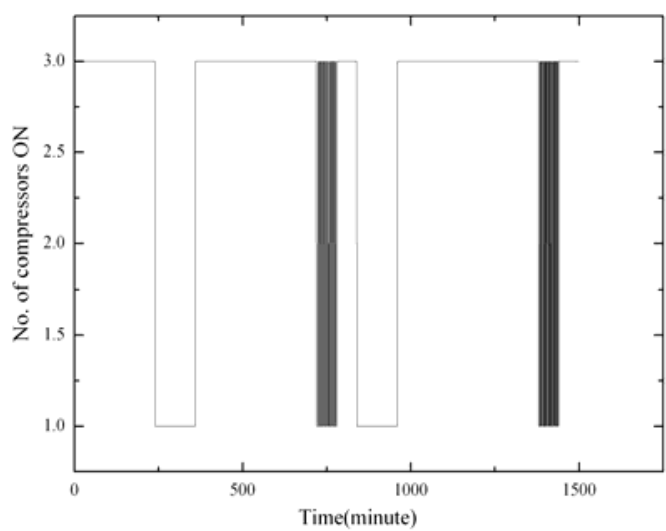

Fig. 7. Number of working compressors

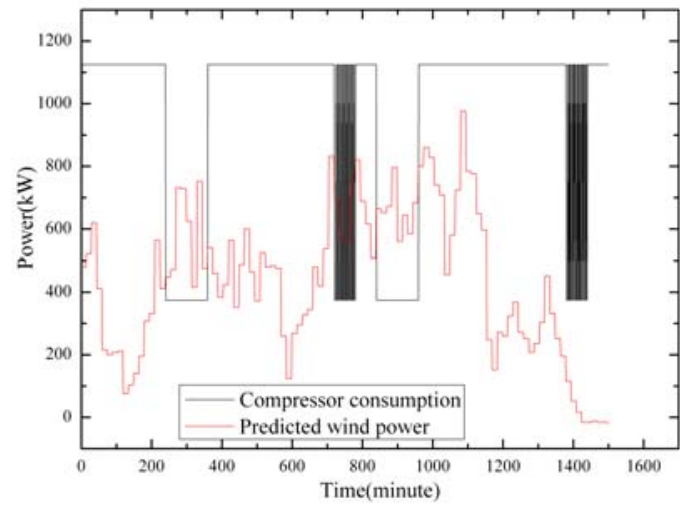

Fig. 8. Compressor consumption and predicted wind power for the next 25 hours

\section{DISCUSSION}

To simulate electrical systems that enable the investigation of interaction between refrigerated warehouses and production from wind turbines, work will continue on integrating the GA based controller with Risø's software IPSYS, which is a flexible frame work for the simulation of integrated energy systems with multiple forms of energy and complex control structures.

The simulations will be carried out for a system located in a region where there is a high penetration of wind energy, i.e. there is sufficient wind energy to make a noticeable impact on the operation of the system and therefore on the price of electricity. In this way, the results would not only primarily be focused on the assessment of financial potential for refrigerated warehouse owners, but could also be used to scale up to a European level to give an idea of how much wind power would be used in refrigerated warehouse storage if all of them implemented the control based on GA.

\section{CONCLUSION}

It is clearly demonstrated that a GA approach is both feasible and advantageous for load management in refrigerated warehouses in a system with wind power penetration.

It can provide the owner of refrigerated warehouses with a set of time-ordered investment decisions which is not obtained from static optimizations, but directly from the consideration of the time dimension of the problem.

Furthermore, it allows non-linear characteristics and stochastic events to be handled which are hard to include in pure mathematical model methods; in fact, the existence of non-linearities and stochastics enhance the advantages of using GA when compared to pure mathematical programming. These non-linearity and stochastic arise not only from the non-linear and stochastic character of objective functions and constraints, but also from the discrete, stochastic nature of many aspects of the wind energy for the Demand Side Management (DSM) in the power grid.

The results of a GA are generation of solutions, filtered through the competition for survival. Therefore, many interesting and valuable scenarios can be executed; helping the owner or end user to gain insight into the problem he is facing to and allowing better decisions to be taken.

\section{ACKNOWLEDGMENT}

This paper describes work that builds upon work carried out by CENER within the Night Wind project.

\section{REFERENCES}

[1] Declan Butler. (2007, 7 February). Fridges could save power for a rainy day-Turning off cold storage could buffer the electricity grid Available: http://www.nature.com/news/2007/070205/full/0702059.html

[2] Tom Cronin, Henrik Bindner, Carsten Hansen, Oliver Gehrke, Mikel Iribas Latour and Monica Aguado, et al. 
"Increasing wind power penetration by advanced control of cold store temperatures," in Proc. Conf. Nordic Wind Power, Roskilde, Denmark, 2007, pp. 199-204.

[3] D. E. Goldberg, Genetic Algorithm in Search, Optimization and Machine Learning. Reading, MA: Addison-Wesley, 1989, pp. 1-15

[4] E. Pettit and K. M. Swigger, "An analysis of genetic-based pattern tracking," in Proc. National Conf. on Al, AAAI 83, 1983. pp. 327-332.

[5] Matthew Wall. (1996, August). GAlib: A C++ Library of Genetic Algorithm Components. Version 2.4. Available: http://lancet.mit.edu/ga/

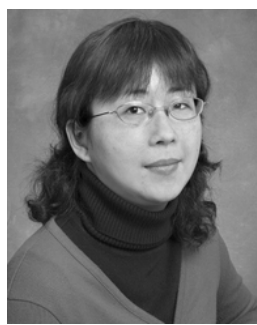

Yi Zong was born in Wuhan in the Hubei province, China, on August 21, 1971. She got Ph.D on System Engineering and Automation in 2006 at the University Complutense of Madrid, Spain.

Her employment experience included the Wuhan Institute of Technology, China. Since 2006 she has been employed at the Wind Energy Division of Risoe, National Laboratory for Sustainable Energy, Technical University of Denmark (Risoe DTU). Her special fields of interest included intelligent control and intelligent instruments.

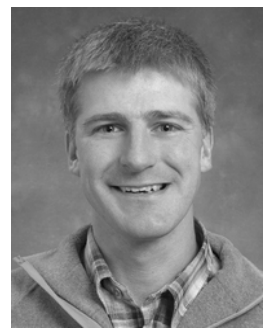

Tom Cronin was born in Boston, Massachusetts, USA, on $24^{\text {th }}$ September 1967. He has an Engineering degree from Bristol University, England, and a MSc in Renewable Energy from Loughborough University, England.

$\mathrm{He}$ worked for many years in engineering consultancy firms before joining Risø DTU in 2004, where he carries out research in hybrid wind systems and continues with some consultancy work within wind energy.

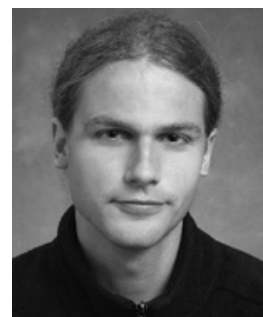

Oliver Gehrke was born in Frankfurt am Main, Germany, on March 15, 1975. He graduated in Electrical Power Engineering from Darmstadt University of Technology and has been pursuing his $\mathrm{PhD}$ degree at Risø National Laboratory in Denmark. $\mathrm{He}$ is currently a scientist at Risø DTU.

His special fields of interest include the embedded and distributed control of power systems with a high penetration of renewable energy sources.

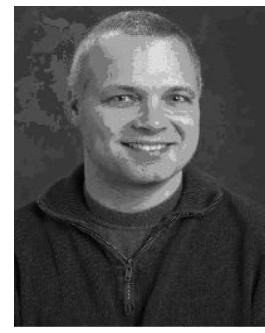

Henrik Bindner was born on 30 June 1964 in Copenhagen, Denmark. He received his master in electrical engineering from the Technical University of Denmark in 1988. Since 1990 he has been with Risø DTU National Laboratory for Sustainable Energy in the Wind Energy Division, currently as a Senior Scientist.

He has mainly been working on integration of wind energy into power system. The work has included analysis, design and control of small island systems as well as technologies and techniques for integration of wind in large systems. Currently, he is researching how distributed energy resources can be applied to increase penetration of wind energy.

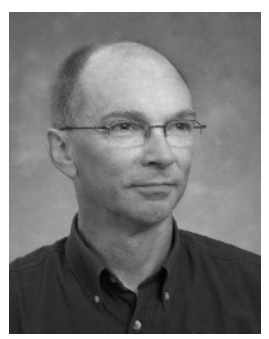

Jens Carsten Hansen has 31 years of professional experience as an engineer and scientist, and has since 1982 been employed at the Wind Energy Division of Risoe National Laboratory for Sustainable Energy, Technical University of Denmark (Risoe DTU). Since year 2000 he has been the Manager of Risoe WindConsult and since 2002 he has been the head of the Wind Energy Systems research programme. The work as a scientist has primarily been within technological research in wind power applications and as such undertaken in parallel with activities as consultant in international wind power projects.

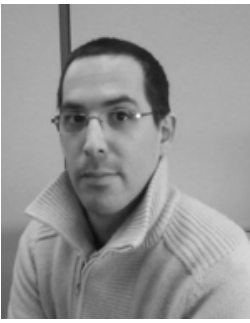

Mikel Iribas Latour was born in Pamplona in Spain, on January 7, 1976. He received his Degree on Industrial Engineer in 2001 at the Universidad Publica de Navarra, in Pamplona, Spain.

His employment experience included the Asociación de la Industria Navarra and Associated Professor at the Universidad Pública de Navarra, at the Automatic and Computational Department Since 2004 he is working as a researcher at the Renewable Energy National Centre, CENER, of Spain. His currently research interest is on Wind Turbine Control and Identification, Robust and Adaptive Control.

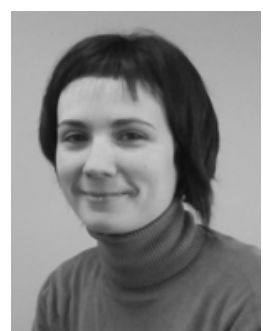

Oihane Usunariz Arcauz was born in Pamplona, on December 24, 1981. She received his Degree on Industrial Engineer in 2005 at the Universidad Pública de Navarra, in Pamplona.

Her employment experience included Andritz Küsters $\mathrm{GmbH}$, and Schoolteacher at IES Politécnico Tafalla in Navarra. Since 2006 she is working as a researcher at the Renewable Energy National Centre, CENER. Her currently interest is on Hardware In the Loop, RTOS and development of RT software. 